濒小水滴の蒸発速度についで

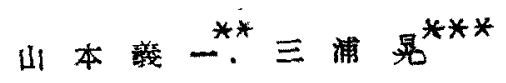

81 䊑言

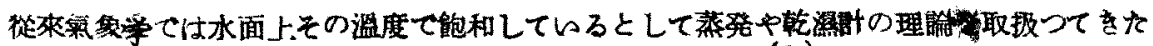

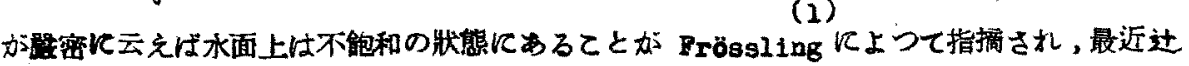

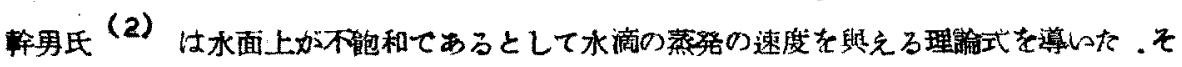

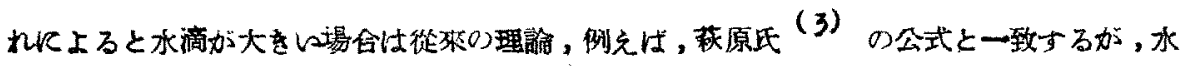

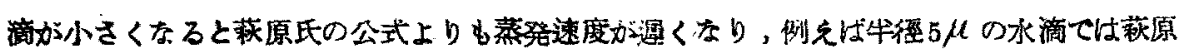

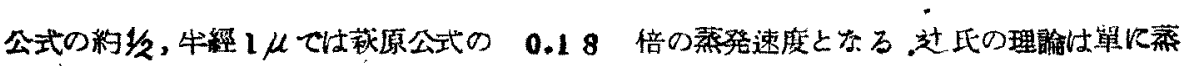

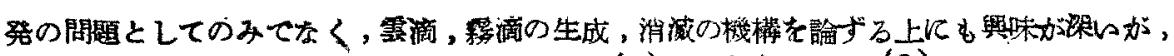

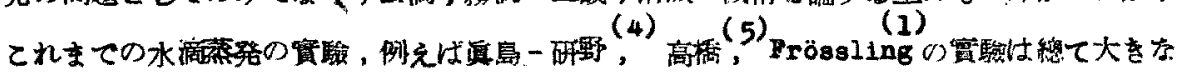

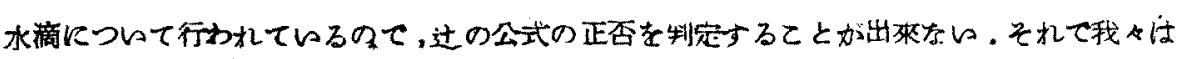

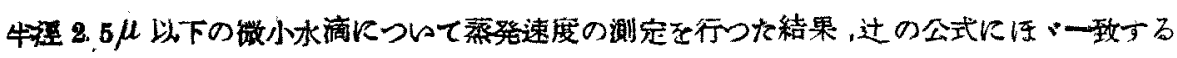
絬果を得てのてててて報告しよう

竫止水滴の蒸努速度を與元る式としては放原氏により

$$
\frac{d m}{d t}=-\frac{4 \pi D M}{R T}\left(P_{0}-P_{\infty}\right) a
$$

て然充られている

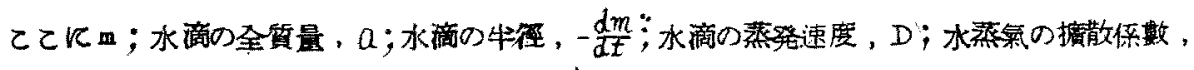

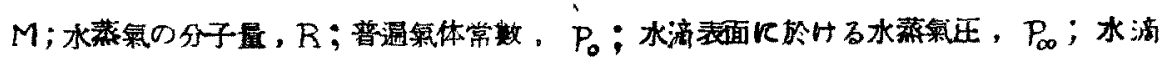
上り充分雄れて堨所の水蒸锥である

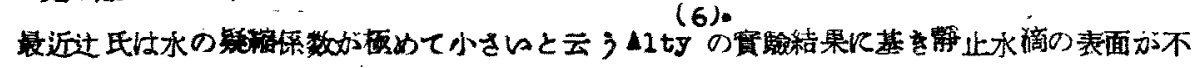

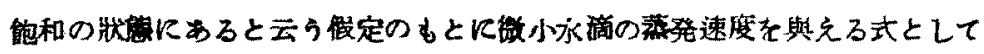

支提出した

$$
\frac{d m}{d t}=-\frac{4 \pi D M}{R T\left(1+\frac{D}{K a}\right)}\left(P_{s}-P_{\infty}\right) a
$$

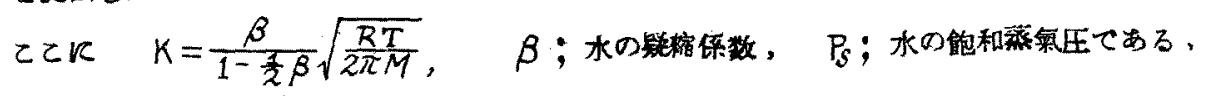

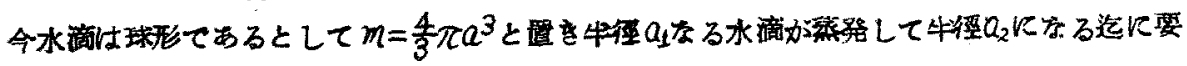
する時間を老とすれば

$(1) \pm b$

* G. Yamamoto and A. Miurar On the Rate of Evaporation of Small Mater Drops. Erops.

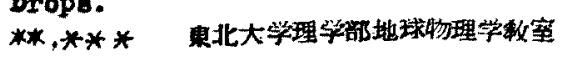


(2)上り

$$
t_{12}=\int_{a_{1}}^{a_{2}} \frac{R T a d a}{D M\left(P_{0}-P_{\infty}\right)}=\frac{R T}{2 D M\left(P_{0}-P_{\infty}\right)}\left(a_{1}^{2}-a_{2}^{2}\right)
$$

$$
t_{12}=\int_{a_{1}}^{a_{2}} \frac{B T a}{D M\left(P_{S}-P_{\infty}\right)}\left(1+\frac{D}{K a}\right) d a=\frac{B T}{2 D M\left(P_{S}-P_{\infty}\right)}\left(a_{1}^{2}-a_{2}^{2}\right)+\frac{R T}{K M\left(P_{S}-P_{\infty}\right)}\left(a_{1}-a_{2}\right)
$$

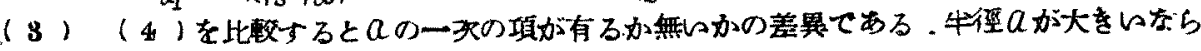

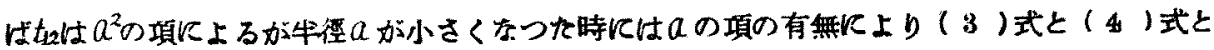
の差は大をくる

\section{2 葢输法と測完秸果}

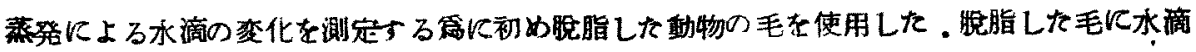

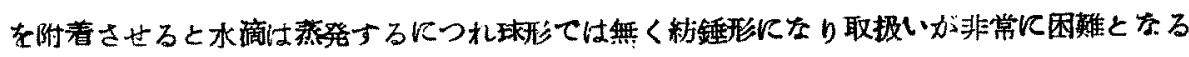
更に動物の毛は尖端ても3〜 $5 \mu$ のささが有るのて

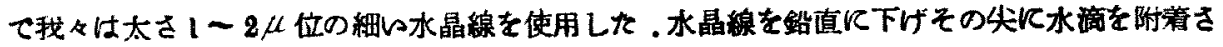

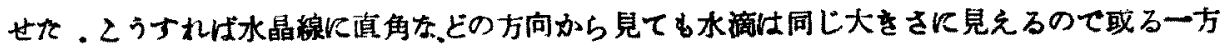

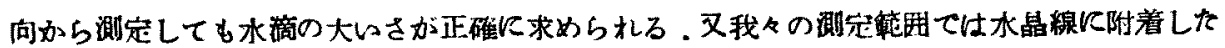

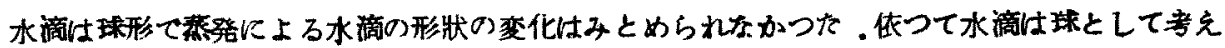

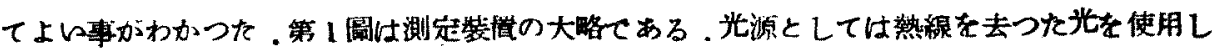

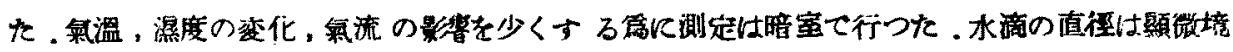

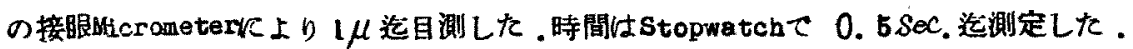

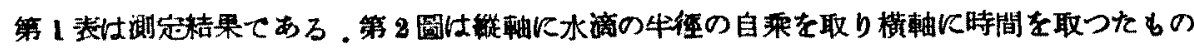

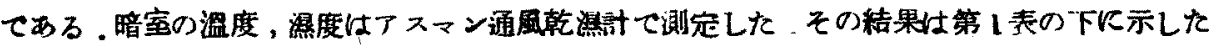

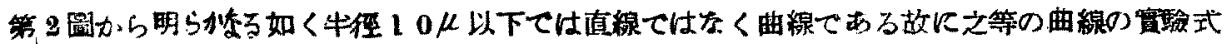

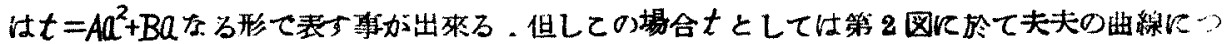

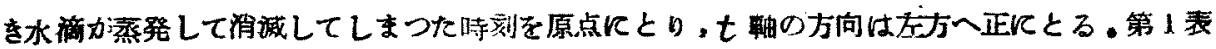

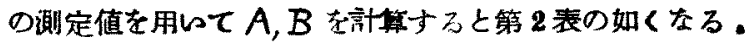

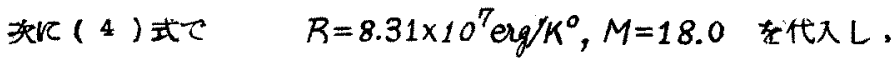

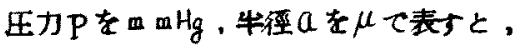

$$
t_{12}=1.74 \times 10^{-5} \frac{T}{D\left(P_{s}-P_{\infty}\right)}\left(a_{1}^{2}-a_{2}^{2}\right)+4.04 \times 10^{-4} \frac{\sqrt{T}}{\alpha\left(P_{s}-P_{\infty}\right)}\left(a_{1}-a_{2}\right) \text {, 但 } L \alpha=\frac{\beta}{1-\frac{\beta}{2}}
$$

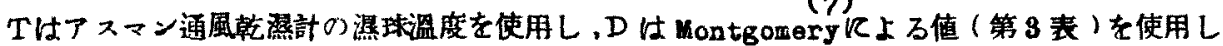

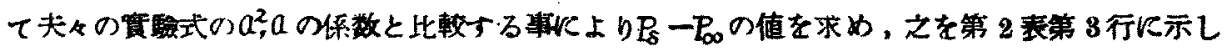
te

又このP

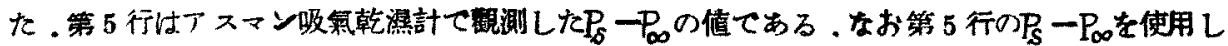

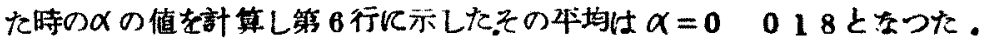


第 1 㽞

测定裝置

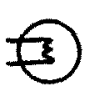

半瀑
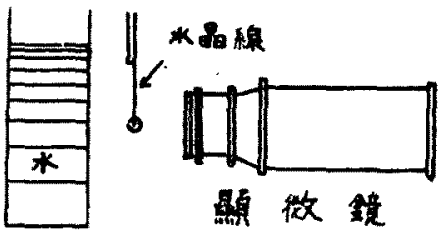

照 微 理

\section{3 結率}

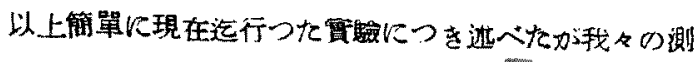

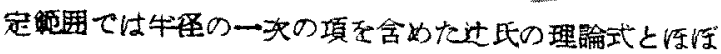
一致与る結果得た。朗ち水滴の表面は館和世与不能和

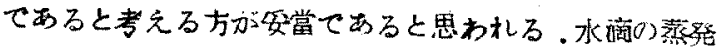

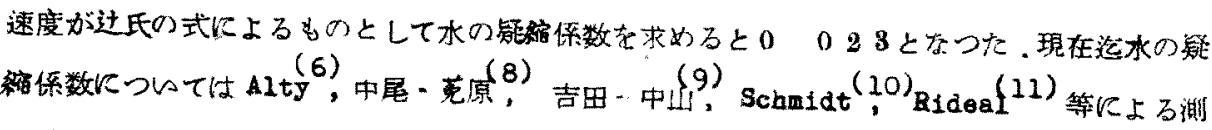

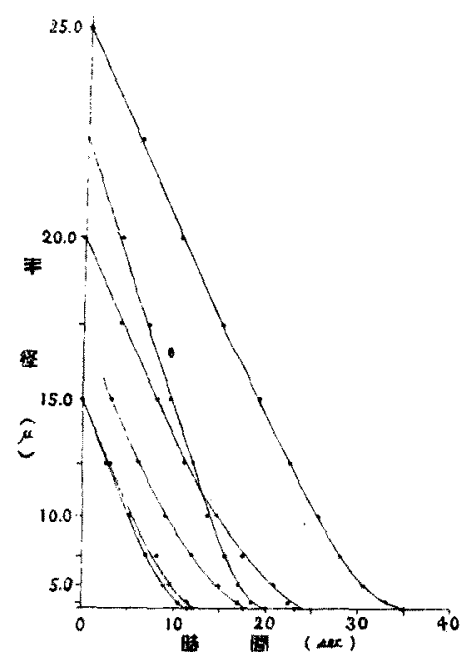

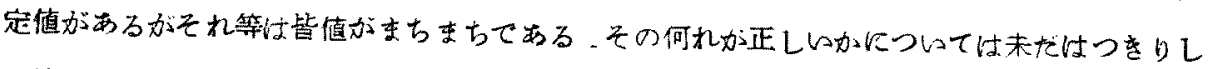

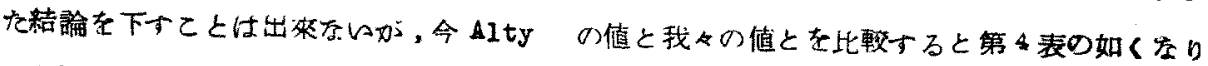
任骤一政する

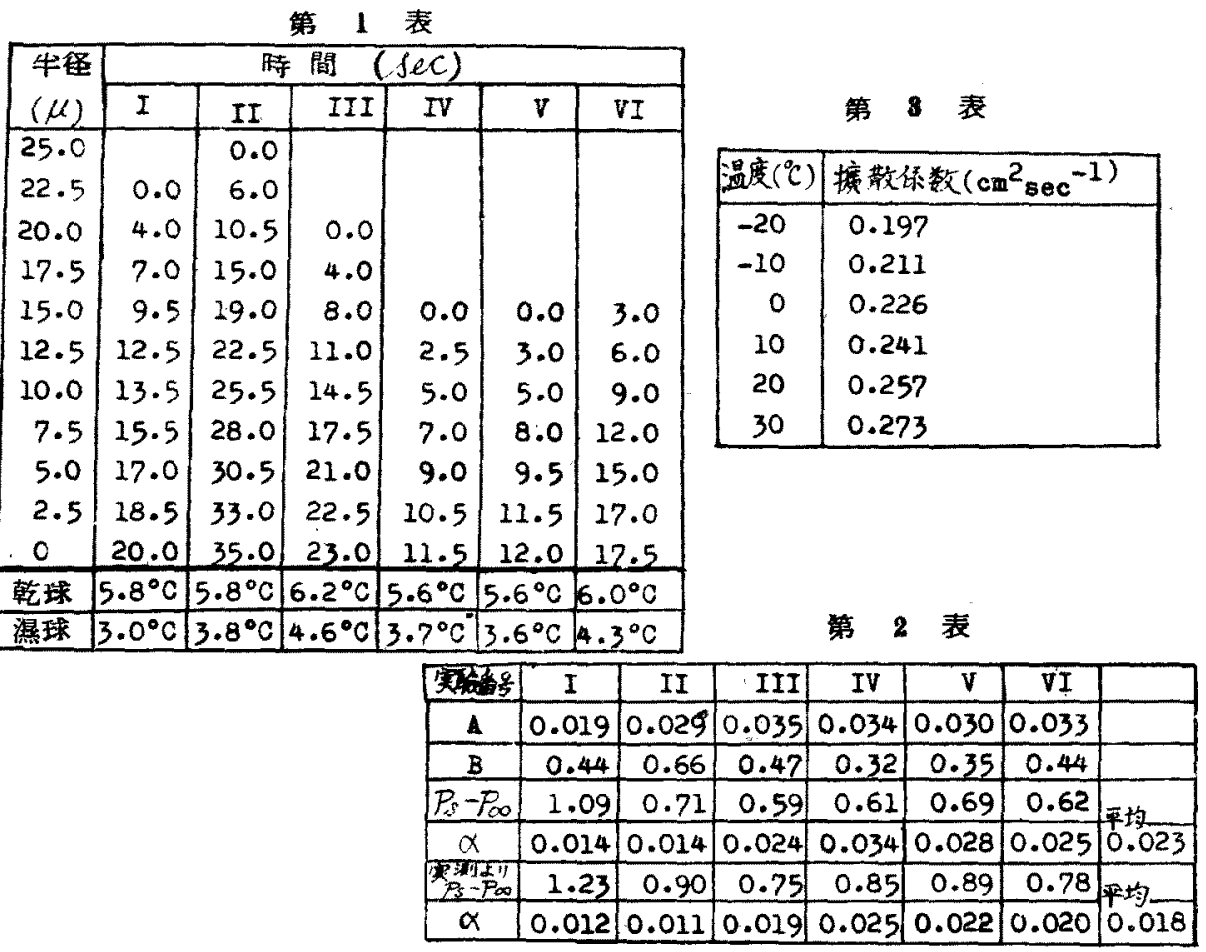


躬 4 变

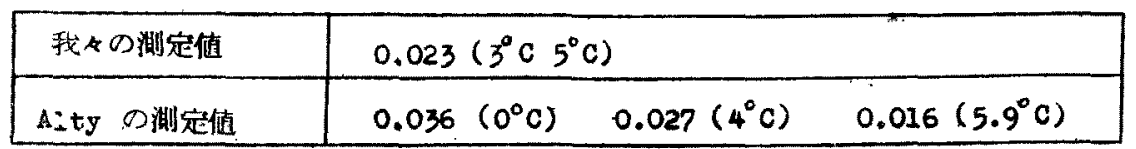

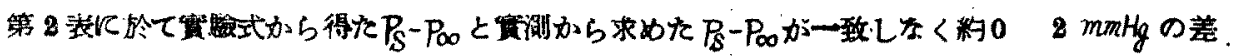

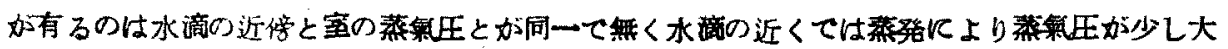

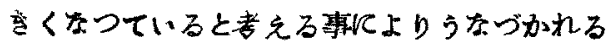

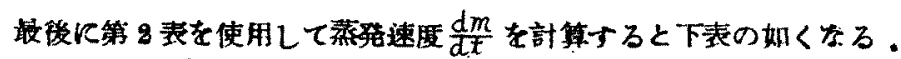

\begin{tabular}{|c|c|c|c|c|c|}
\hline 保 $(\mu)$ & 50 & 40 & 30 & 20 & 10 \\
\hline$\frac{d m}{d t}\left(\mu^{3} / \mathrm{soc}\right)$ & $9.0 \times 10^{3}$ & $6.6 \times 10^{3}$ & $4.8 \times 10^{3}$ & $2.9 \times 10^{3}$ & $1.2 \times 10^{3}$ \\
\hline
\end{tabular}

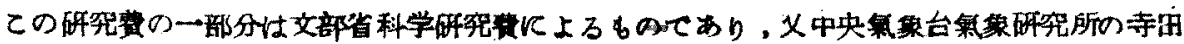

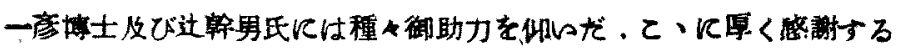

女 就

(1) Frögsiling : Gorl. Beit. z. Gophys., 52 (1938) 170

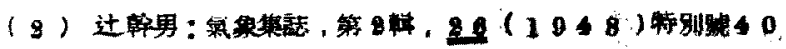

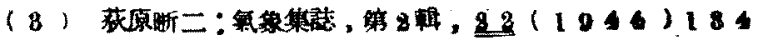

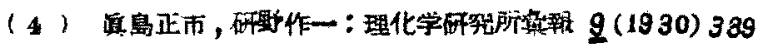

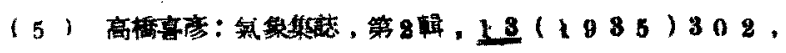

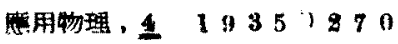

(a) Alty: Proc. Roy. Soc., (A) 149 (1935) 104

(7) Montgonery: Jour. Meteo., 4 (1947) 193

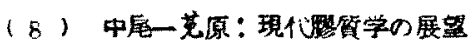

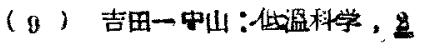

(Ifi) Schmidt " Techn. Mech. Thermodynaulk", I (1930) 2

(11) Rideal : J, Phys . Chem., 29 (1925) 1585

(昭棅24年5月13日㛺理) 